\title{
Finding Romantic Images in Gynecological Pathology: Valentine Heart Shaped Uterus
}

\author{
Simona Stolnicu', Iulia Barsan'1, Cristian Podoleanu², Claudiu Molnar ${ }^{3}$ \\ 1 Department of Pathology, University of Medicine and Pharmacy, Tîrgu Mureș, Romania \\ 2 Department of Internal Medicine IV, University of Medicine and Pharmacy, Tîrgu Mureș, Romania \\ ${ }^{3}$ Department of Gynecology, University of Medicine and Pharmacy, Tîrgu Mureș, Romania
}

\section{CORRESPONDENCE \\ Cristian Podoleanu \\ Str. Gheorghe Marinescu nr. 38 \\ 540139 Tîrgu Mureș, Romania \\ Tel +40 265215551 \\ E-mail: podoleanu@me.com}

\section{ARTICLE HISTORY}

Received: 23 August, 2016

Accepted: 8 September, 2016
Simona Stolnicu • Str. Gheorghe Marinescu nr. 38 540139 Tîrgu Mureș, Romania. Tel +40 265215551 Iulia Barsan • Str. Gheorghe Marinescu nr. 38, 540139 Tîrgu Mureș, Romania. Tel +40 265215551

Claudiu Molnar • Str. Gheorghe Marinescu nr. 38 540139 Tîrgu Mures, Romania. Tel +40 265215551
A 79-year-old patient presented to the Gynecology Clinic for pelvic pain at the beginning of February. Clinical and ultrasound examination revealed the presence of a large and partially cystic uterine mass. Macroscopic examination of the surgical specimen revealed the presence of a $13 \mathrm{~cm}$ diameter, heart shaped cystic mass involving the uterine corpus. On the cut surface, multiple polypoid areas of yellow color and soft consistency were partially infiltrating the myometrium and the uterine cervix. Microscopically, the lesion was diagnosed as FIGO grade 2 endometrioid adenocarcinoma of the uterus (Figure 1).

Each year on February $14^{\text {th }}$, many people around the world exchange cards, candy, gifts, flowers and enjoy romantic dinner with their special "valentine". This day of romance called Valentine's Day is named for a Christian martyr and dates back to the $5^{\text {th }}$ century, but according to some modern sources it originates in the mid-February Roman holiday Lupercalia devoted to fertility and love. ${ }^{1}$ The most common symbol of Valentine's day is a heart, particularly in red or pink.

In our case, the red heart shaped uterus was due to an endometrioid adenocarcinoma, the most common malignant tumor of the uterus. ${ }^{2}$ This tumor is most of the times exophytic even when deeply invasive, and can be composed of separate polypoid masses, like in our case. Enlargement of the uterus usually occurs due to the myometrial invasion, and extension into the lower uterine segment is common, whereas involvement of the cervix occurs only in $20 \%$ of the cases. In our particular case, the tumor infiltrated the lower uterine and the cervical segment, producing the obstruction of the latter, which secondarily determined the cystic dilatation of the uterine cavity, reproducing the shape of a Valentine heart, a phenomenon that has never been previously reported in endometrial pathology.

\section{ACKNOWLEDGMENT}

The authors are grateful to Dr. Cosmin Moldovan from the Department of Histology, University of Medicine and Pharmacy of Tîrgu Mureș for his substantial contribution to the processing of the graphic files. 

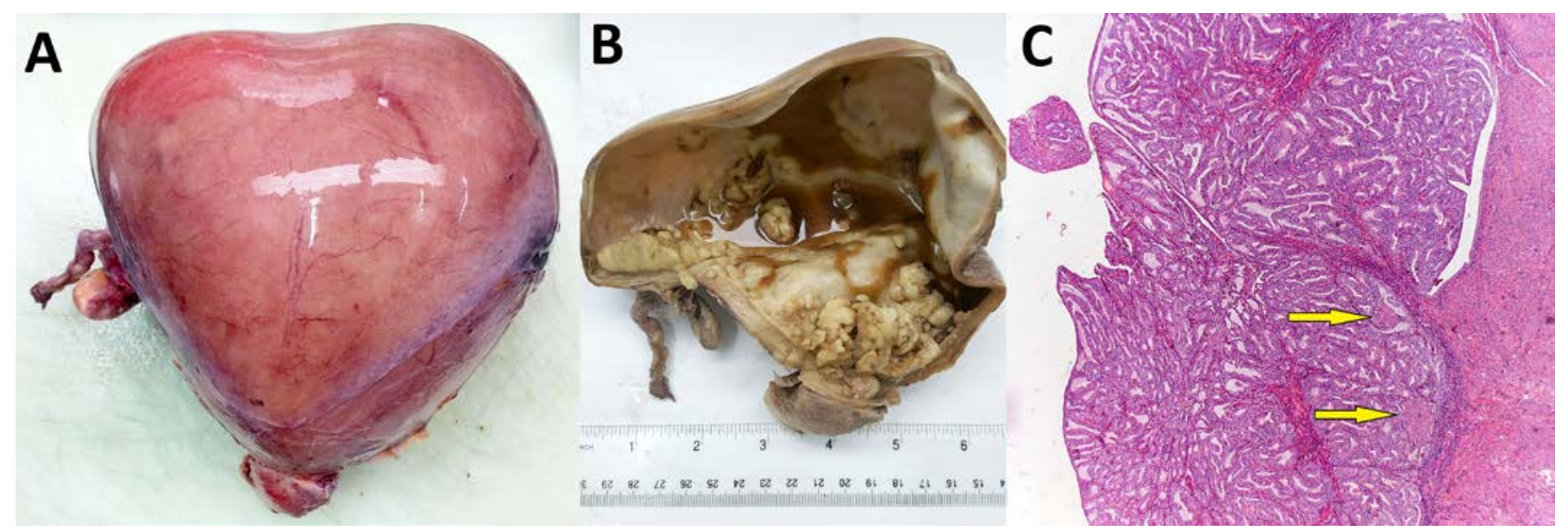

FIGURE 1. Heart shaped uterine corpus (A), due to a polypoid area of yellow color and soft consistency, partially infiltrating the myometrium and the uterine cervix (B) and microscopically represented by a proliferation of atypical glands infiltrating the endometrium and associated with morules (yellow arrow) (C).

\section{CONFLICT OF INTEREST}

Nothing to declare.

\section{REFERENCES}

1. Kelly Henry Ansgar. Chaucer and the cult of Saint Valentine. Leiden: E.J. Brill. 1986. pg. 46-58

2. Kurman RJ, Carcangiu ML, Herrington CS, Young RH, eds. WHO Classification of Tumours of Female Reproductive Organs. $4^{\text {th }}$ edition. IARC: Lyon 2014. 